look forward to the involvement of Doctors Hall, Swann and other old age psychiatrists!

Francis Creed

University of Manchester

School of Psychiatry and

Behavioural Sciences

Manchester M13 9WL

\section{Comparative costs of adult acute psychiatric services}

DEAR SIRS

Peck and Cockburn on Cost Comparison (Psychiatric Bulletin, - February 1993, 17, 79-81) cannot be taken seriously. The authors admit to having conducted a methodologically weak study of DGH based adult psychiatric service with various community services which only looked at cost with scant regard to the quality of care.

It was indeed a very small sample. A great pity that only four out of 13 supposedly innovative community services gave good enough financial information for comparison. They admit that the costs are imprecise. At any rate, only two out of these four (Community Services 2 and 4 ) seemed to provide at first glance a comparable range of treatments to the hospital model. The quality of service is not at all known, nor is there any mention of the opinions of the patients, carers and GPs as to how useful these services are.

While it is easy to agree that the capital costs of a bed based service are indeed going to be higher, even from the authors' own figures (Table IV), it is impossible to agree that the revenue costs are significantly greater in the hospital service and that hospitals have any greater appetite for revenue consumption.

The revenue costs given are mistakenly reported to be highest in the hospital based service. The authors' own table provides very clear evidence that even with the highest bed usage, the hospital based service costs per 10,000 population at $£ 170,000$, are in the middle of the costs range of the four community comparisons which work out between $£ 130,000$ and $£ 1,000,000$ (see Table). The comparable services cost $£ 130,000$ and $£ 1,000,000$, the latter showing about six times higher revenue costs than the hospital model.

It does seem that the authors perhaps in their own preference towards community "models" of service failed to notice correctly what their own figures are clearly telling them. One hopes that they will quickly rectify their conclusion lest the anti-hospital enthusiasts and uncritical observers get unduly excited, and the health managers raise their hopes at these flawed conclusions. We all need much more comprehensive costs and quality analysis in papers to generate an informed debate.
TABLE

Comparative revenue costs per 10,000 population

$\begin{array}{ll}\text { Community service } 2^{*} & 130,000 \\ \text { Community service } 4 & 150,000 \\ \text { DGH based service } & 170,000 \\ \text { Community service } 1 & 270,000 \\ \text { Community service } 3^{*} & 1,000,000\end{array}$

( ${ }^{*}$ Comparable provisions to $\mathrm{DGH}$ )

Bierley Hall Hospital

Kumud S. Bhatnagar Bradford BD46QA

\section{Reply}

DEAR Sirs

(Editor's Note: We regret that the final figure in Column 3 of Table IV should have read 100,000 and not $1,000,000$.)

I am grateful for the opportunity to reply to Dr Bhatnagar's letter. The major thrust of his argument is undermined by the correction noted above. I will deal briefly with his other points.

We endeavoured to ensure that the services being compared were attempting to deal with the same range of needs. We were deliberately modest in our claims for the paper and made no attempt to do a cost - benefit analysis; however Dean $\&$ Gadd have reported on the apparent satisfaction of users and carers with Community service 2 replicating the findings of both Stein \& Hoult in this respect. Furthermore, Community service 4 was the end result of a very thorough process of consultation with users and carers as well as the traditional stakeholders, such as psychiatrists. Unfortunately limitations on space precluded us exploring these issues in more depth.

Dr Bhatnagar accuses the authors of a preference for community models - in my case any such preference is the result of over six years of listening to users discussing their needs and preferred solutions. Within such models the challenge is to construct an effective balance between community and hospital.

\section{Centre for Mental Health \\ Services Development \\ King's College London \\ London W87 AH}

\section{Training in liaison psychiatry}

\section{DEAR SIRS}

The recommendations of the Liaison Psychiatry Group Executive Committee (1993) on this subject were interesting. In Melbourne there is a well established tradition of consultation liaison psychiatry 